\title{
Humanização: a Essência da Ação Técnica e Ética nas Práticas de Saúde
}

\author{
Humanization: the Essence of Technical and Ethical \\ Action in Health
}

Izabel Cristina Rios ${ }^{1}$

\author{
PALAVRAS-CHAVE \\ - Humanização. \\ - Ética. \\ - Gestão. \\ - Violência. \\ - Políticas públicas. \\ - Práticas assistenciais.
}

\section{KEYWORDS}

- Humanization.

- Ethics.

- Management.

- Violence.

- Public policies.

- Practices of health care.

Recebido em: 24/06/2008

Aprovado em: 08/09/2008

\section{RESUMO}

O presente artigo discute o surgimento da humanização no contexto histórico e cultural de nossa época no momento em que a sociedade pós-moderna passa por uma revisão de valores e atitudes. Aprofunda o conceito de humanização e apresenta suas principais vertentes: a humanização como movimento contra a violência institucional na área da saúde, como princípio de conduta de base humanista e ética, como política pública para a atenção e gestão no SUS, como metodologia auxiliar para a gestão participativa, como tecnologia do cuidado na assistência à saúde. Nessa perspectiva, humanização é o processo, fundamentado no respeito e valorização da pessoa humana, que visa à transformação da cultura institucional por meio da construção coletiva de compromissos éticos e de métodos para as ações de atenção à saúde e de gestão dos serviços. Sua essência é a aliança da competência técnica e tecnológica com a competência ética e relacional. O texto discute brevemente as dificuldades para realizar a humanização no cotidiano da vida institucional e no ensino médico.

\begin{abstract}
This article discusses the emergence of humanization in the contemporary historical and cultural context, at a time when post-modern society is reviewing values and attitudes. The author analyzes the concept of humanization in depth and presents its main approaches: humanization as a movement against institutional violence in the health field, as a principle for humanist and ethical conduct, as a public policy for health care and management in the Unified National Health System (SUS), as a methodology to support participatory management, and as a health care technology. From this perspective, humanization is the process - based on respect and valuation of the individual - that aims to transform institutional culture through the collective development of ethical commitments and methods for action in health care and services management. The essence is the alliance between technical and technological competence and ethical and relational competence. The article briefly discusses the difficulties in achieving humanization in daily institutional life and medical education.
\end{abstract}




\section{INTRODUÇÃO}

A humanização é hoje um tema frequente nos serviços públicos de saúde, nos textos oficiais e nas publicações da área da Saúde Coletiva.

Embora o termo laico "humanização" possa guardar em si um traço maniqueísta, seu uso histórico o consagra como aquele que rememora movimentos de recuperação de valores humanos esquecidos ou solapados em tempos de frouxidão ética. Em nosso horizonte histórico, a humanização desponta, novamente, no momento em que a sociedade pós-moderna passa por uma revisão de valores e atitudes. Não é possível pensar a humanização na saúde sem antes dar uma olhada no que acontece no mundo contemporâneo...

Numa visão panorâmica, a época da pós-modernidade ${ }^{1,2}$ se caracteriza pelo reordenamento social decorrente do capitalismo multinacional e pela globalização econômica. Desabaram os ideais utópicos, políticos, éticos e estéticos da modernidade que creditavam ao projeto iluminista a construção de um mundo melhor movido pela razão humana. As pessoas, cada vez mais descrentes da política e das ideias revolucionárias que, na prática, deram poder a governos corruptos e incapazes de promover o bem da nação, não buscaram mais seus referenciais de identificação nos grandes coletivos sociais, mas, sim, em si mesmas. Para certos autores, essa é uma das principais características do que chamam de época hipermoderna ou supermoderna ${ }^{3,4}$ : a figura do excesso e da deformação notadamente ao que se refere ao "eu".

Nessa vertente, Lasch dá aos tempos atuais o nome de Cultura Narcísica, e Debors, de Sociedade do Espetáculo ${ }^{5,6}$, ora ressaltando o individualismo, o culto ao corpo e a supervalorização dos aspectos da aparência estética, ora ressaltando o exibicionismo, a captura pela imagem e o comportamento histriônico que se realiza como espetáculo.

No campo das relações, a perda de suportes sociais e éticos, somada ao modo narcísico de ser, cria as condições para a intolerância à diferença, e o outro é visto não como parceiro ou aliado, mas como ameaça. Tal disposição, associada à rapidez e ao pouco estímulo à reflexão sobre os aspectos existenciais e morais do viver humano, faz com que a violência - que (por motivos que fogem ao alcance deste artigo) é parte do nosso cotidiano - se apresente também como modo de resolver conflitos.

No contraponto, do meio do século XX para cá, começam a se desenhar respostas para a sociedade assim estabelecida. Direitos humanos, bioética, proteção ambiental, cidadania, mais que conceitos emergentes ${ }^{7}$, são práticas que vão ganhando espaço no dia-a-dia das pessoas, chamando-nos para o trabalho de construção de outra realidade.
Na área da saúde, surgiram várias iniciativas com o nome de humanização. É bem provável que esse termo tenha sido forjado há umas duas décadas, quando os acordes da luta antimanicomial, na área da Saúde Mental ${ }^{8,}$ e do movimento feminista pela humanização do parto e nascimento, na área da Saúde da Mulher ${ }^{9}$, começaram a ganhar volume e a produzir ruído suficiente para registrar marca histórica.

Desde então, vários hospitais, predominantemente do setor público, começaram a desenvolver ações que chamavam de "humanizadoras". Inicialmente, eram ações que tornavam o ambiente hospitalar mais afável: atividades lúdicas, lazer, entretenimento ou arte, melhorias na aparência física dos serviços. Não chegavam a abalar ou modificar substancialmente a organização do trabalho ou o modo de gestão, tampouco a vida das pessoas, mas faziam o papel de válvulas de escape para diminuir o sofrimento que o ambiente de trabalho hospitalar provoca em pacientes e trabalhadores. Pouco a pouco, a ideia foi ganhando consistência, resultando em alterações de rotina (por exemplo, visita livre, acompanhante, dieta personalizada).

Em 2001, quando a Secretaria de Estado da Saúde de São Paulo fez um levantamento dos hospitais públicos do Estado que desenvolviam ações humanizadoras, praticamente todos faziam alguma coisa nesse sentido. O mesmo se verificou em 94 hospitais de referência no País escolhidos pelo Ministério da Saúde, praticamente na mesma época. A iniciativa partia dos próprios trabalhadores, independentemente de incentivo ou determinação dos gestores locais. Tratava-se de uma resposta a uma necessidade sentida e reconhecida pelas pessoas em seus ambientes de trabalho.

Hoje, várias sondagens conceituais, manifestações ideológicas, construções teóricas e técnicas e programas temáticos fazem da humanização um instigante campo de inovação da produção teórica e prática na área da saúde ${ }^{10}$.

Sob vários olhares, a humanização pode ser compreendida como:

- Princípio de conduta de base humanista e ética;

- Movimento contra a violência institucional na área da saúde;

- Política pública para a atenção e gestão no SUS;

- Metodologia auxiliar para a gestão participativa;

— Tecnologia do cuidado na assistência à saúde.

Em nosso entender, a humanização se fundamenta no respeito e valorização da pessoa humana, e constitui um processo que visa à transformação da cultura institucional por meio da construção coletiva de compromissos éticos e de métodos para as ações de atenção à saúde e de gestão dos serviços. Esse con- 
ceito amplo abriga as diversas visões da humanização supracitadas enquanto abordagens complementares que permitem a realização dos propósitos para os quais aponta sua definição.

A humanização reconhece o campo das subjetividades como instância fundamental para a melhor compreensão dos problemas e para a busca de soluções compartilhadas. Participação, autonomia, responsabilidade e atitude solidária são valores que caracterizam esse modo de fazer saúde que resulta, ao final, em mais qualidade na atenção e melhores condições de trabalho. Sua essência é a aliança da competência técnica e tecnológica com a competência ética e relacional.

\section{HUMANIZAÇÃO E ÉTICA}

"Humanizar o quê? Por acaso não somos humanos?" (auxiliar de enfermagem de uma UBS da SMS-SP)

Há alguns anos, quando o assunto humanização chegou aos serviços de saúde, a reação dos trabalhadores foi variada. Algumas pessoas (que já trabalhavam com ações humanizadoras) sentiram-se finalmente reconhecidas e encontraram seus pares, mas a maioria (que não fazia a mínima ideia do que se tratava) reagiu com desdém ou com indignação. Não eram humanos afinal? Humanizar os serviços soava como um insulto. Entretanto, tão logo se começava a discutir a humanização como o processo de construção de uma ética relacional que recuperava valores humanísticos esmaecidos pelo cotidiano institucional ora aflito, ora desvitalizado, ficava clara a importância de trazer tal discussão para o campo da saúde. A medicina (e certamente todas as profissões que se destinam ao cuidar) é uma prática ético-dependente ${ }^{11}$, ou seja, ainda que o mundo se acabe em um livre agredir, em que vença o mais forte, o mais rico ou o mais bonito, na área da saúde é imprescindível a educação para a ética nas relações entre as pessoas, sem a qual não é possível realizar a missão que nos destina essa escolha profissional.

Humanizar, então, não se refere a uma progressão na escala biológica ou antropológica, o que seria totalmente absurdo, mas o reconhecimento da natureza humana em sua essência e a elaboração de acordos de cooperação, de diretrizes de conduta ética, de atitudes profissionais condizentes com valores humanos coletivamente pactuados.

No sentido filosófico, humanização é um termo que encontra suas raízes no Humanismo ${ }^{12}$, corrente filosófica que reconhece o valor e a dignidade do homem, este a medida de todas as coisas, considerando sua natureza, limites, interesses e potenciais. O Humanismo busca compreender o homem e criar meios de se compreender uns aos outros.

Na leitura psicanalítica, o termo fala do lugar da subjetividade no campo da saúde. Humanização, enquanto tornar humano, significa admitir todas as dimensões humanas - históricas, sociais, artísticas, subjetivas, sagradas ou nefastas - e possibilitar escolhas conscientes e responsáveis.

A Psicanálise se encontra com o Humanismo quando coloca no centro de seu campo de investigação, compreensão e intervenção o homem e sua natureza humana (que pode ser tão divina quanto demoníaca... No mais das vezes, as duas... $\mathrm{Na}$ melhor das hipóteses, a primeira cuidando para que a segunda se mantenha o mais quieta possível). A natureza humana comporta pulsões para a construção e para a agressão. Em nossa essência, temos potencial para agir tanto num sentido quanto no outro. O julgamento ético de cada ato e a sua escolha são tarefa psíquica constante, que põe em jogo os valores que a cultura nos dá por referência e os desejos que se ocultam no íntimo de cada um. Reconhecer a importância dessas características humanas é o primeiro passo para a humanização.

O segundo passo é desenvolver métodos que permitam a inserção de tais aspectos humanos no pensar e agir sobre os processos saúde-adoecimento-cura e nas relações de trabalho. Trata-se de criar espaços legítimos de fala e escuta que devolvam à palavra sua potência reveladora e transformadora ${ }^{13}$.

Na relação do profissional com o paciente, a escuta não é só um ato generoso e de boa vontade, mas um imprescindível recurso técnico para o diagnóstico e a adesão terapêutica. $\mathrm{Na}$ relação entre profissionais, esses espaços são a base para o exercício da gestão participativa e da transdisciplinaridade.

Na vertente moral, a humanização pode evocar valores humanitários, como respeito, solidariedade, compaixão, empatia, bondade (valores morais ${ }^{7}$ pensados como juízos sobre as ações humanas que as definem como boas ou más, representando determinada visão de mundo num dado tempo e lugar e, portanto, mutáveis de acordo com as transformações da sociedade). A humanização propõe a construção coletiva de valores que resgatem a dignidade humana na área da saúde e o exercício da ética, aqui pensada como um princípio organizador da ação. O agir ético, neste ponto de vista, se refere à reflexão crítica que cada um de nós, profissionais da saúde, tem o dever de realizar, confrontando os princípios institucionais com os próprios valores, modo de ser e pensar e agir no sentido do bem... Claro que seria um ato de violência se, em nome da humanização, determinássemos quais os valores pessoais que cada um deve ter. Entretanto, na dimensão institucional, trata-se de valores fundamentais para balizar a atitude profissional de todos com diretrizes éticas que expressem o que, coletivamente, se considera bom e justo.

A ética, assim pensada, torna-se um importante instrumento contra a violência e a favor da humanização. 


\section{HUMANIZAÇÃO E VIOLÊNCIA INSTITUCIONAL}

Em sua história, a humanização surge, então, como resposta espontânea a um estado de tensão, insatisfação e sofrimento tanto dos profissionais quanto dos pacientes, diante de fatos e fenômenos que configuram o que chamamos de violência institucional na saúde (violência institucional ${ }^{14}$ aqui se refere à expressão cunhada na história recente para definir a utilização de castigos, abusos e arbitrariedades praticados nas prisões, escolas e instituições psiquiátricas, com a conivência do Estado e da sociedade).

$\mathrm{Na}$ área da saúde, a violência institucional decorre de relações sociais marcadas pela sujeição dos indivíduos. Historicamente, a organização hierárquica do hospital do século XIX foi uma importante estratégia da medicina da época moderna ${ }^{14}$ para o desenvolvimento da clínica e da tecnologia médica. Aumentou o acesso da população ao atendimento e propiciou grandes avanços técnicos. Entretanto, junto a esses progressos, também se engendraram situações que tornaram o hospital um lugar de sofrimento ${ }^{15}$. O não reconhecimento das subjetividades envolvidas nas práticas assistenciais no interior de uma estrutura caracterizada pela rigidez hierárquica, controle, ausência de direito ou recurso das decisões superiores, forma de circulação da comunicação apenas descendente, descaso pelos aspectos humanísticos e disciplina autoritária fizeram do hospital um lugar onde as pessoas são tratadas como coisas e prevalece o não respeito à sua autonomia e a falta de solidariedade ${ }^{15}$.

A própria organização científica do trabalho (fortemente presente na área da saúde) fragmenta o processo que vai do início ao fim da produção seja de bens, seja de serviços, deixando cada etapa do processo a cargo de um grupo de trabalhadores que acabam tendo apenas a visão da parte que lhes cabe e não do todo. Essa estratégia agiliza e multiplica o resultado, mas cria um estado de alienação quanto à importância de cada um para a realização completa da tarefa. $\mathrm{Na}$ área da saúde, isto acarreta a naturalização do sofrimento e a diminuição do compromisso e da responsabilidade na produção da saúde.

Desenha-se, assim, um cenário social e institucional em que a falta de sensibilidade e de valores humanísticos abre espaço para que o comportamento violento - expresso em atos de brutalidade explícita ou sofisticados disfarces da intolerância e do desprezo - passe a ser a norma e não a exceção.

Outro fator que contribui para esse estado de coisas é a medicalização do viver humano. Inicialmente, a medicalização se referia à transformação de problemas sociais em problemas de saúde. Por exemplo: antes de encarnar no corpo, a "fome" é um problema da pobreza ou da educação, depois de um tempo vira "desnutrição". Combater a fome é diferente de tratar a desnutrição do ponto de vista social (uma coisa é dar atenção à saúde, outra é mudar a distribuição de renda). Aos poucos, a medicalização foi abrangendo problemas que em épocas anteriores não teriam a medicina como destino, mas, sim, outras áreas do saber. Com o aumento da crença das pessoas no que consideram verdades científicas na área da saúde e a decadência do valor socialmente dado às outras formas de compreensão da existência humana, toda e qualquer expressão da vida passa por um diagnóstico previsto em algum CID (Código Internacional das Doenças) e busca remédio na medicina. Assim, toda tristeza vira depressão, toda inquietação vira ansiedade e todo mundo procura os serviços de saúde atrás de respostas rápidas e deglutíveis, mesmo que não funcionem...

Ao lado desse fenômeno cultural da contemporaneidade, em nossa realidade, o sucateamento dos serviços de saúde devido à má gestão da coisa pública ou aos sempre insuficientes investimentos frente aos crescentes custos da medicina biotecnológica levou à pletora do acesso aos serviços e ao esgotamento dos profissionais para atender. Filas intermináveis, pacientes mal atendidos por profissionais mal remunerados e desvalorizados, e todo tipo de conflito passaram a ser comuns nessa arena assim armada.

Como já dito, a humanização surgiu em resposta a esse enredo, sob a forma de ações localizadas, e foi se instituindo até chegar, hoje, à forma de uma política pública na área da saúde. Não por acaso, a humanização une suas primeiras vozes nos hospitais, fazendo coro a um movimento contrário à situação em que há aqueles que mandam e decidem, e outros que obedecem e não opinam sobre nada. Nesse sentido, a humanização buscava nas ações humanizadoras a recuperação não só da saúde física, mas principalmente do respeito, do direito, da generosidade, da expressão subjetiva e dos desejos das pessoas.

\section{HUMANIZAÇÃO COMO POLÍTICA PÚBLICA PARA A ATENÇÃO E GESTÃO NO SUS}

A humanização nasceu dentro do SUS. Os princípios do SUS ${ }^{16}$ são totalmente de inspiração humanista: universalidade, integralidade, equidade e participação social. Levados às últimas consequências, definem a humanização em qualquer concepção, em qualquer instância de atenção ou gestão. Tal caráter faz do SUS, hoje, o principal sistema de inclusão social deste país.

Enquanto na maioria dos hospitais privados a humanização foi tratada como cosmética da atenção - recepcionistas jovens e bonitas, bem vestidas e maquiadas, ambientes bem decorados que não devem nada aos hotéis de luxo, frigobar no quarto e lojinha de conveniência -, nos hospitais públicos e movimentos sociais a humanização escapa aos modelos comerciais e recupera dos ideais do SUS a prática da cidadania. 
Quase 20 anos depois de sua criação, o SUS é o sistema idealizado para os anseios de saúde do povo brasileiro, mas é também o sistema de saúde público que apresenta as contradições e heterogeneidades que caracterizam nossa sociedade: serviços modernos e de ponta tecnológica ao lado de serviços sucateados nos quais estão presentes a cronificação do modo obsoleto de operar o serviço público, a burocratização e os fenômenos que caracterizam situações de violência institucional.

No ano 2000, o Ministério da Saúde, sensível às manifestações setoriais e às diversas iniciativas locais de humanização das práticas de saúde, criou o Programa Nacional de Humanização da Assistência Hospitalar (PNHAH). Esse programa estimulava a disseminação das ideias da humanização, os diagnósticos situacionais e a promoção de ações humanizadoras de acordo com realidades locais. Inovador e bem construído por um grupo de psicanalistas, o programa tinha forte ênfase na transformação das relações interpessoais pelo aprofundamento da compreensão dos fenômenos no campo das subjetividades.

Em 2003, o Ministério da Saúde passou o PNHAH por uma revisão e lançou a Política Nacional de Humanização $(\mathrm{PNH})^{16}$, que mudou o patamar de alcance da humanização dos hospitais para toda a rede SUS e definiu uma política cujo foco passou a ser principalmente os processos de gestão e de trabalho. Enquanto política, a PNH se apresenta como um conjunto de diretrizes transversais que norteiam toda atividade institucional que envolva usuários ou profissionais da saúde, em qualquer instância de efetuação. Tais diretrizes apontam como caminho:

- a valorização da dimensão subjetiva e social em todas as práticas de atenção e gestão, fortalecendo compromissos e responsabilidade;

- o fortalecimento do trabalho em equipe, estimulando a transdisciplinaridade e a grupalidade;

- a utilização da informação, comunicação, educação permanente e dos espaços da gestão na construção de autonomia e protagonismo;

- a promoção do cuidado (pessoal e institucional) ao cuidador.

Nessa vertente, a humanização focaliza com especial atenção os processos de trabalho e os modelos de gestão e planejamento, interferindo no cerne da vida institucional, local onde de fato se engendram os vícios e os abusos da violência institucional. O resultado esperado é a valorização das pessoas em todas as práticas de atenção e gestão, a integração, o compromisso e a responsabilidade de todos com o bem comum.

Para sua implementação ${ }^{16}$, a PNH atua nos eixos de institucionalização que operaram a mudança de cultura a que se propõe. Tais eixos compreendem a inserção das diretrizes da humanização nos planos estaduais e municipais dos vários governos, nos programas de Educação Permanente, nos cursos profissionalizantes e instituições formadoras da área da saúde, na mídia, nas ações de atenção integral à saúde, no estímulo à pesquisa relacionada ao tema, vinculando-os ao repasse de recursos.

Várias ações e indicadores de validação e monitoramento foram desenvolvidos pelo Ministério da Saúde para estimular e acompanhar os processos de humanização não só nos hospitais, mas nos três níveis de atenção à saúde no SUS. A estratégia de criação e fortalecimento dos Grupos de Trabalho de Humanização nas instituições - grupos formados por pessoas ligadas ao tema e aos gestores dos serviços de saúde, com o papel de implementar a PNH em sua unidade - mostrou-se exitosa em vários locais, acumulando muitos bons exemplos de trabalho na área.

Entretanto, a humanização só se torna realidade numa instituição quando seus gestores fazem dela mais que retórica, um modelo de fazer gestão. Boas intenções e programas limitados a ações circunstanciais não sustentam a humanização como processo transformador. Os instrumentos que de fato asseguram esse processo são a informação, a educação permanente e a gestão participativa.

Enfim, pensar a humanização enquanto política significa menos o que fazer e mais como fazer. Embora importantes, não são necessariamente as ações ditas humanizadoras que determinam um caráter humanizado ao serviço como um todo, mas a consideração dos princípios conceituais que definem a humanização como a base para toda e qualquer atividade. Este é o grande desafio: criar uma nova cultura de funcionamento institucional e de relacionamentos na qual, cotidianamente, se façam presente os valores da humanização.

\section{HUMANIZAÇÃO E GESTÃO PARTICIPATIVA}

Com a PNH, a humanização alcança os processos de gestão e organização do trabalho nos serviços de saúde, e a gestão participativa desponta como modelo eleito para a realização dessa política. Quando falamos em gestão participativa ou cogestão, estamos nos referindo ao modo de administrar que não se basta na linha superior de comando e inclui o pensar e o fazer coletivos ${ }^{17}$.

As estratégias para a gestão participativa nos serviços de saúde devem ser estudadas caso a caso, partindo do conhecimento das realidades institucionais específicas, mas algumas ações que a propiciam em qualquer contexto são:

- a criação de espaços de discussão para a contextualização dos impasses, sofrimentos, angústias e desgas- 
tes a que se submetem os profissionais de saúde no dia-a-dia pela natureza de seu trabalho;

- o pensar e decidir coletivamente sobre a organização do trabalho, envolvendo gestores, usuários e trabalhadores em grupos com diversas formações;

- a criação de equipes transdisciplinares efetivas que sustentem a diversidade dos vários discursos presentes na instituição, promovendo o aproveitamento da inteligência coletiva.

De modo mais específico, a gestão participativa se dá por meio da criação de instâncias de participação nas quais é possível considerar e estabelecer consensos entre desejos e interesses diversos, como, por exemplo:

- o conselho gestor de saúde, que aglutina gestores, trabalhadores e usuários para decidir os rumos institucionais;

- a ouvidoria, que faz a mediação entre usuários e instituição para a solução de problemas particulares;

- as equipes de referência, que se compõem de profissionais que juntos acompanham pacientes comuns ao grupo;

- os grupos de trabalho de humanização, que fazem a escuta institucional e criam dispositivos comunicacionais;

- as visitas abertas, que propiciam as parcerias com familiares para o cuidado de seus parentes.

Algumas ferramentas, como as pesquisas de satisfação dos usuários e dos trabalhadores ou as pesquisas de clima institucional e de fatores psicossociais do trabalho (FPST), podem ser bastante úteis para certos diagnósticos institucionais e para o planejamento da ambiência (ambiente físico, social, interpessoal) e da organização dos processos de trabalho. Os FPST ${ }^{18}$ são dimensões referentes a gestão, organização e relações interpessoais no trabalho, que no ambiente físico e relacional podem produzir a satisfação e o sentimento de realização, ou, no seu revés, o sofrimento e o adoecimento do trabalhador. Permitem estudar como os trabalhadores percebem a instituição, privilegiando o olhar subjetivo da experiência do trabalho na vida das pessoas em determinado tempo e lugar. Os fatores psicossociais, que relacionam saúde e satisfação no trabalho, abrangem: estabilidade no emprego, salários e benefícios, relações sociais no trabalho, supervisão e chefia, ambiente físico de trabalho, reconhecimento e valorização, oportunidades de desenvolvimento profissional, conteúdo, variedade e desafio no trabalho, qualificação, autonomia, subutilização de habilidades e competências, carga de trabalho (física, cognitiva ou emocional).
Particularmente importantes são as estratégias, metodologias e ferramentas que se destinam ao desenvolvimento do profissional da área da saúde. Acreditamos que a possibilidade de promover atendimentos verdadeiramente humanizados requer, necessariamente, a educação dos profissionais da saúde dentro dos princípios da humanização e o desenvolvimento de ações institucionais que visem ao cuidado e à atenção às situações de sofrimento e estresse decorrentes do próprio trabalho e ambiente em que se dão as práticas de saúde.

Nessa direção, a Educação Permanente ${ }^{19}$ é uma estratégia para o exercício da gestão participativa que visa à transformação das práticas de formação, de atenção e de gestão na área da saúde. Baseada na aprendizagem significativa, a educação permanente constroi os saberes a partir das experiências das pessoas. Nas rodas de conversa, oficinas e reuniões, discutemse os problemas, propõem-se soluções gerenciais, mudanças na organização do trabalho e definem-se ações educativas de acordo com as necessidades observadas.

Dessa maneira, faz-se da gestão participativa o caminho para a humanização dos serviços. Entretanto, como há poucos gestores com formação técnica para essa metodologia, ainda são raras as experiências dessa forma inovadora de fazer gestão de pessoas.

\section{HUMANIZAÇÃO E TECNOLOGIA DO CUIDADO NA ASSISTÊNCIA À SAÚDE}

$\mathrm{Na}$ assistência à saúde, a supremacia do recorte biológico e o autoritarismo dos discursos de saber e poder deflagraram crítica contundente ao modelo biomédico de atenção. No aprofundamento do estudo das situações conjunturais associadas a esse fato, chegou-se ao que se pensa hoje sobre a humanização na vertente da indissolubilidade da relação entre atenção e gestão. Por outra linha do pensar (que também se articula com o que expusemos até aqui), o foco ilumina a relação do profissional da saúde com o paciente e o resultado desse encontro.

Na medicina, o tecnicismo da prática atual descartou os aspectos humanísticos no cuidado à saúde ${ }^{12}$. A biotecnologia aplicada à medicina propiciou indiscutíveis conquistas para o bem das pessoas (alguém hoje consegue imaginar um procedimento cirúrgico, até mesmo de pequeno porte, sem anestesia, por exemplo?). Estudos mostram que os recursos tecnológicos, a visão centrada nos aspectos biológicos da doença e a organização do trabalho médico para o atendimento de massa ampliaram o acesso da população aos bens e serviços de saúde, mas, em compensação, criaram um abismo entre o médico e o paciente.

A tecnologia, que é determinante para aumentar a sobrevida humana e para a diminuição drástica do sofrimento devido 
aos males que acometem a saúde, tornou-se um intermediário que afasta os profissionais do contato mais próximo e mais demorado com o paciente, não só porque agiliza o atendimento e aumenta a produtividade contada em números, mas também porque fascina e captura o interesse dos profissionais da saúde, particularmente dos médicos. Os pacientes passam, então, à condição de objetos de estudo e manipulação na construção do saber e da prática "científica". E os profissionais, à condição de peças e engrenagens que fazem funcionar a máquina institucional. $\mathrm{O}$ tecnicismo perde de vista estados vivenciais importantes para a realização do cuidado à saúde.

Já no modelo psicossocial, agregam-se saberes de teorias compreensivas sobre o vínculo capazes de desvendar atitudes e emoções que facilitam ou impedem o bom diagnóstico e a aliança terapêutica ${ }^{10,20}$. Por exemplo, a Psicanálise ensina que, ao adoecer, a pessoa vive um processo que chamamos de regressão narcísica ${ }^{21}$, que, em graus variáveis de acordo com a história pessoal, a personalidade e a gravidade de sua doença, a torna mais frágil, mais sensível e mais dependente daquele que lhe presta cuidados. É como se o paciente, inconscientemente, voltasse aos tempos em que era cuidado pela mãe e dela dependia para sobreviver. Desconsiderar esse estado ou tratar o paciente com displicência, superficialidade ou mesmo pressa e desatenção às suas emoções não é só uma falha ética, mas, sim, um erro técnico que pode provocar danos no paciente e o fracasso do tratamento. Por outro lado, não se trata de entender o paciente como infantilizado e desconsiderar sua autonomia, o que seria, além de antiético, o descumprimento de um direito dos usuários de serviços de saúde ${ }^{22}$. Ou seja, não basta bom senso e paciência, é preciso que o profissional aprenda teorias e técnicas relacionais.

Entretanto, mesmo conscientes da importância do campo da subjetividade na saúde, da ênfase dada ao princípio da integralidade e do desenvolvimento de tecnologias leves destinadas ao aprimoramento da atenção, particularmente no campo da atenção básica à saúde ${ }^{20}$, para a maioria dos profissionais, o modo tecnicamente humanizado permanece uma utopia - aquele que seria o jeito certo de fazer, mas não dá ou não adianta.

O grande nó ainda não desatado talvez tenha a ver com a necessidade de desenvolver nos profissionais o interesse legítimo pelo paciente. Tarefa nada fácil nos tempos atuais, em que, como discutido anteriormente, prevalece o individualismo e o jeito narcísico de ser, inclusive na formação acadêmica dos profissionais da saúde.

\section{HUMANIZAÇÃO E ENSINO MÉDICO}

Embora a PNH tenha como um de seus eixos de implementação a inserção das diretrizes da humanização nas esco- las formadoras de profissionais da área da saúde, na prática, sua presença no ensino superior ainda é pálida e sôfrega.

No ensino médico, há algum tempo, várias escolas daqui e de outras partes do mundo colocaram disciplinas de humanidades médicas em seus currículos de graduação. As experiências são bem heterogêneas, mas é comum a dificuldade de integrar os temas humanísticos ao escopo da medicina ${ }^{23}$. Ainda que essenciais à boa prática médica, para muitos alunos e professores as disciplinas de humanidades médicas são tidas como prescindíveis e desinteressantes.

A humanização se inscreve como um tema nessas disciplinas, mas frequentemente é abordada de forma superficial e periférica. Em nossa experiência de trabalho numa disciplina de humanidades, percebemos que os alunos desconhecem completamente a abrangência significativa da humanização nas práticas de saúde. Ao final das discussões sobre o tema, mostramse bastante surpresos ao descobrirem que se trata de algo bem mais complexo e bem mais diretamente ligado ao exercício da medicina do que as ideias de "ser bonzinho", "ser educado" e "agradar ao paciente" que trazem em suas associações ao tema e traduzem preconceito e descaso com o que mal conhecem.

Por outro lado, embora muitos hospitais-escola tenham Comitês de Humanização, o tema ainda é relativamente recente no cotidiano da maioria das práticas de atenção e ensino ${ }^{15}$. Sobre esta questão, no Seminário Internacional de Gestão - Mostra SES-SP de 2008, uma pesquisa realizada com residentes do primeiro e último ano da residência médica do Hospital Heliópolis, da Secretaria de Estado da Saúde de São Paulo ${ }^{24}$, - para a qual convergem alunos formados em diferentes escolas do Estado - revelou dados curiosos. Ao ingressarem na residência, os médicos apresentavam vaga noção do que seria humanização, considerando-a mais focada na qualidade da relação médico-paciente. Na saída, a maioria deles apresentou maior falta de informação e de interesse pelo assunto, inclusive considerando que a humanização tem menos a ver com o seu trabalho e mais com o serviço de voluntários, a administração hospitalar, psicólogos e assistentes sociais.

Esses achados corroboram nossas observações no que se refere não só à timidez com que o tema está inscrito na formação médica, como ao fato de que ainda é prevalente nos hospitais a ideia da humanização voltada para ações pontuais que amenizam as tensões cotidianas da vida intra-hospitalar. Outra observação importante é que, além de não ter havido acréscimo em seu aprendizado ao longo da residência, houve uma distorção do que trata a humanização e a sua importância no trabalho médico.

Estudos que vão ao encontro da compreensão do papel da tecnologia e das mudanças sociais do trabalho médico ${ }^{11}$ ou do 
atendimento hospitalar ${ }^{15}$ mostram que as transformações tecnológicas da medicina e o modo como se organiza hoje o trabalho médico não favorecem o discurso e a prática da humanização. A própria mudança do $\mathrm{PNHAH}$ para a $\mathrm{PNH}$ - que aumenta o campo iluminado da humanização, mantendo foco nas relações intersubjetivas, mas acentuando a necessidade de mudar processos de gestão e organização do trabalho na área da saúde - tem como base a realidade descrita nesses e noutros trabalhos.

Parece fundamental que o ensino da humanização na formação médica deve partir da conscientização do tema em todos os âmbitos nos quais se dá o aprendizado. É preciso que os hospitais-escola desenvolvam a PNH em seu dia-a-dia, ao mesmo tempo em que as disciplinas de humanidades curriculares trabalhem seus conteúdos com os alunos, num verdadeiro movimento de integração serviço-escola.

Outro aspecto fundamental para o desenvolvimento da humanização no ensino médico é a inclusão de seus princípios e diretrizes na gestão educacional e a presença de espaços de construção de subjetividade, escuta e exercício de reflexão sobre a vida de estudante e de médico, como se observa nos programas de tutoria ${ }^{25}$.

Na condição de espaços nos quais se cultiva o vínculo, o respeito à diferença de opinião, a construção coletiva de ideias e juízos sobre os mais diversos temas do cotidiano médico, os programas de tutoria são lócus privilegiados para o cultivo da humanização no ensino médico. Cenário que abriga histórias de vida, vivências comuns ao estudante de Medicina, situações que podem estar na frente ou atrás dos panos e que podem e devem ser conscientemente abordadas, trocando o cinismo pela ética.

\section{DO CAMINHO PERCORRIDO AO QUE AINDA TEMOS QUE PERCORRER...}

No tempo em que na medicina havia poucos recursos para o diagnóstico e tratamento, a presença do médico ao lado do paciente, observando-o minuciosamente, acompanhando sua evolução, ampliando o conhecimento acerca de sua vida e hábitos, era necessária ao próprio exercício da profissão $0^{11}$. Essa atitude, mais próxima ao que hoje se postula para a humanização das práticas, não era algo da ordem do amor ao próximo, como, ingenuamente, uma certa visão romântica tende a insinuar. Vários relatos da história da medicina mostram o grande interesse científico dos médicos na busca de soluções para os males do corpo, alguns levados pelo altruísmo, outros pela vaidade ${ }^{26}$. Durante muito tempo, a proximidade com o paciente era quase um imperativo técnico para o exercício da boa medicina ${ }^{11}$.

As mudanças sociais e culturais que atravessaram os tempos desde essa época transformaram a face da medicina e das práticas de saúde, chegando ao contexto que discutimos neste artigo e suas implicações no surgimento da humanização na saúde. Começando por ações isoladas, pontuais, amadoras, a humanização foi desenvolvendo conceitos e tecnologias para sua aplicação tanto no campo das relações profissionais-pacientes, quanto no campo da gestão, chegando à forma de política pública na saúde.

Entretanto, a falta de compreensão mais profunda da dimensão psicossocial que envolve os processos saúde-doença, a falta de compromisso com o resultado do trabalho, a falta de decisões compartilhadas com pacientes, de projetos assistenciais discutidos em equipe multidisciplinar, e mesmo de gestão participativa nos serviços de saúde, tornam a humanização do cuidado um projeto ideal ainda bem distante da realidade dos serviços de saúde.

Trabalhamos durante vários anos junto aos hospitais públicos da Secretaria de Estado da Saúde coordenando a Área de Humanização e pudemos observar que, além desses problemas estruturais referentes principalmente à gestão dos serviços, há um outro lado do problema que, menos evidente e mais entranhado na cultura dos serviços, também dificulta muito as mudanças de comportamento que a humanização advoga. Trata-se do que cada profissional espera de sua profissão. Para muitos, o trabalho é o dever a ser cumprido para dar direito ao salário. Para outros, é também caminho para a satisfação pessoal, a superação de desafios, o prazer de ser alguém que faz diferença na vida dos outros e na própria vida.

Da nossa experiência e ponto de vista, a humanização só terá assegurado seu lugar na relação do profissional com o paciente quando se mostrar indispensável aos bons resultados que o profissional deseja de si mesmo em seu trabalho ${ }^{27}$. Para isso, há que se provocar (se é que isto é possível) uma descoberta fundamental na vida dos profissionais de saúde... A recuperação do desejo e do prazer de cuidar, algo que, de tão distante dos valores culturais que predominam na contemporaneidade, parece irremediavelmente perdido, mas quem sabe...

Aí, então, a necessidade de bem cuidar será sentida como uma disposição que pode mover o desejo de aprender um outro jeito de ser e fazer o encontro clínico no campo intersubjetivo e, mais além deste, realizar a humanização em toda a sua amplitude.

\section{REFERÊNCIAS}

1. Anderson P. As origens da pós-modernidade. Rio de Janeiro: Zahar; 1999.

2. Lyotard JF. A condição pós-moderna. Rio de Janeiro: J. Olympio; 2002.

3. Lipovetsky G. Os tempos hipermodernos. São Paulo: Barcarolla; 2004 
4. Augé M. Não lugares: introdução a uma antropologia da supermodernidade. São Paulo: Papirus; 2005.

5. Birman J. Mal estar na atualidade. Rio de Janeiro: Civilização Brasileira; 2001.

6. Costa JF. O vestígio e a aura: corpo e consumismo na moral do espetáculo. Rio de Janeiro: Garamond; 2004.

7. Schramm FR, Rego STA, Braz M, Palácios M. Bioética, riscos e proteção. Rio de Janeiro, Ed. UFRJ; Ed. Fiocruz; 2005.

8. Reis AOA, Marazina I, Gallo PR. A humanização na saúde como instância libertadora. Saúde soc. 2004;13(3):36-43.

9. Diniz CSG. Humanização da assistência ao parto no Brasil: os muitos sentidos de um movimento. Ciênc. saúde coletiva. 2005;10(3):627-37.

10. Deslandes SF. Humanização: revisitando o conceito a partir das contribuições da sociologia médica. In: Humanização dos cuidados em saúde. Rio de Janeiro: Ed. Fiocruz; 2006.

11. Schraiber LB. No encontro da técnica com a ética: o exercício de julgar e decidir no cotidiano do trabalho em Medicina. Interface comun saúde educ. 1997.1(1):123-138.

12. Nogare PD. Humanismo e anti-humanismo: introdução à antropologia filosófica. Rio de Janeiro: Vozes; 1977.

13. Volich RM. Entre uma angústia a outra... Boletim de Novidades Pulsional.1995;80:37-45.

14. Foucault M. Microfísica do poder. Rio de Janeiro: Graal; 1986.

15. Sá MC. Em busca de uma porta de saída: os destinos da solidariedade, da cooperação e do cuidado com a vida na porta de entrada de um hospital de emergência. São Paulo; 2005. Doutorado [Tese] - Universidade de São Paulo. Instituto de Psicologia da USP.

16. Brasil. Ministério da Saúde. Secretaria-Executica. Núcleo Técnico da Política Nacional de Humanização. HumanizaSUS: Política Nacional de Humanização do Ministério da Saúde: a humanização como eixo norteador das práticas e gestão em todas as instâncias do SUS. Brasília: Ministério da Saúde; 2004. [Série B. Testos básicos de saúde].

17. Brasil. Ministério da Saúde. Secretaria-Executica. Núcleo Técnico da Política Nacional de Humanização. HumanizaSUS: Gestão participativa e co-gestão [online]. Brasília: Ministério da Saúde; 2004. [Série B. Testos básicos de saúde]. [Acesso em: 24 jun. 2008]. Disponível em: http://dtr2001. saude.gov.br/editora/produtos/impressos/folheto/04_ 1164_FL.pdf

18. Martinez MC. Relação entre satisfação com aspectos psicossociais e saúde dos trabalhadores. Rev.saúde pública. 2004;1(38):55-61.
19. Brasil. Ministério da Saúde. Secretaria de Gestão de Trabalho e da Educação na Saúde. Departamento de Gestão da Educação na Saúde. A educação permanente entra na roda: pólos de educação permanente em saúde: conceitos e caminhos a percorrer [online]. 2. ed. Brasília: Ministério da Saúde; 2005. [Série C. Projetos, programas e relatórios]; [Programa de saúde]. [Acesso em: 24 jun. 2008]. Disponível em: <http://bvsms.saude.gov.br/bvs/publicacoes/ educacao_permanente_entra_na_roda.pdf $>$.

20. Ayres JR. Cuidado: tecnologia ou sabedoria prática. Saúde soc. 2000;6(4)

21. Freud S. Introdução ao Narcisismo. In: Obras psicológicas completas de Sigmund Freud. Edição Standard Brasileira. Rio de Janeiro: Imago; 1988. v. 14. p. 77-108.

22. Brasil. Ministério da Saúde. Carta ao usuário da saúde: ilustrada [online]. Brasília: Ministério da Saúde; 2006. [Série F. Comunicação e educação em saúde]. [Acesso em: 24 jun. 2008]. Disponível em: <http://www.conselho.saude. gov.br/biblioteca/livros/cartaaosusuarios01.pdf > .

23. Rios IC, Lopes Junior A, Kaufman A, Vieira JE, Scanavino MT; Oliveira RA. A integração das disciplinas de humanidades médicas na Faculdade de Medicina da USP - um caminho para o ensino. Rev Bras Educ Med. 2008;32(1)112-121.

24. Mori G, Abramovich I, Monteiro P. Mudança na ótica e na ética das relações durante a residência médica sobre a humanização em saúde [online]. 2007. [Acesso em: 24 jun. 2008] Disponível em: <http://sistema.saude.sp.gov.br/ eventos / Palestras / 28-11-2007\%20-\%20Mostra\%20SES / Comunicacoes\%20Orais/5_Humanizacao\%20nos\%20Serv icos\%20de\%20Saude/Glenda_Garrafa_Mori.pdf $>$.

25. Bellodi PL, Martins MA. Tutoria: mentoring na formação médica. São Paulo: Ed. Casa do Psicólogo; 2005.

26. Thorwald J. O século dos cirurgiões. São Paulo: Ed. Hemus; 2005.

27. Rios IC. Ser e fazer diferente... É possível provocar o desejo? Interface comun saúde educ. 2007;11(26):223-8.

\section{CONFLITO DE INTERESSES}

Declarou não haver

\section{ENDEREÇO PARA CORRESPONDÊNCIA}

Centro de Desenvolvimento de Educação Médica "Prof. Eduardo Marcondes" da Faculdade de Medicina da Universidade de São Paulo

Av. Dr Arnaldo 455

Cerqueira César - São Paulo

CEP.: 01246-903 SP

E-mail: izarios@usp.br 